\title{
Analysing change in an Accident and Emergency Department: organisational routines as ongoing and emergent sociomaterial accomplishments
}

\author{
Norman Crump and Yvonne Latham
}

\begin{abstract}
Bringing together insights from Organisation Studies and Science and Technology Studies this paper provides a multilevel analysis of a planned change initiative. Focusing on different layers of this change the emergent ambiguities, multiplicities and tensions are explored serving to highlight the 'back stage complexities' often hidden by the 'front stage slickness' (Moser and Law) of organisational routines.
\end{abstract}

\section{Introduction}

This paper offers a reading [influenced largely by Science and Technology Studies (STS) traditions of detailed and rich qualitative analysis] of a planned change to everyday organisational routines within an Accident and Emergency (A\&E) department in North West England. This was a change of organisational membership seeking to bring together historically separate groupings of medical professionals, namely hospital-based doctors (emergency medicine consultants and other more junior doctors) and general practitioners (GPs) who work for the majority of their time in a variety of primary care surgeries. The everyday working environment of an A\&E department relies on a great deal of routine. Drawing on literature from Organisation Studies (Cooper and Law, 1995; Feldman, 2000; Orlikowski, 2007) and STS (Star and Griesemer, 1989; Moser and Law, 1999; Law and Singleton, 2005), this routine is perceived as a social and material (sociomaterial) accomplishment with a central role being played by a set of wooden boxes that act as an 'information system' within the department. Focusing on the wooden boxes as this change is being implemented allows for an illumination of some of the ongoing and emergent tensions and contradictions/'back stage complexities' (Moser and Law, 1999) which underpin what are often seen as smooth, everyday routine practices that construct the A\&E department.

$\square$ Norman Crump (n.crump@lancaster.ac.uk) is a Lecturer within the Department of Organisation, Work and Technology at Lancaster University. He has published on aspects of collaborative and technologically mediated work and more recently on developments in managerial concerns with questions of subjectivity. Yvonne Latham (y.l.latham@lancaster.ac.uk) is a Researcher in the Centre for the Study of Technology and Organisation within the Department of Organisation, Work and Technology at Lancaster University. Her research interests include explorations into how the connections between bodies and subjects, and technologies and objects can be understood as emergent and ongoing sociomaterial accomplishments. 
Beginning with a theoretical discussion, a framework is developed with which to explore and analyse the change initiative. This is followed by an empirical discussion outlining the setting and research methodology, leading into an analysis of the initiative itself. Finally some conclusions are drawn and a case is made for the development of this style of analysis, with its focus on the micro practices of routines and their relationship with organisational change.

\section{Theoretical discussion}

The empirical focus of this paper is an organisational change taking place within an A\&E department. Within this department, like many others no doubt, to deal efficiently and indeed calmly with a variety of injuries/illnesses (from the minor to the major) there is a heavy reliance on making what can be a tense and stressful working environment into an everyday (and night) routine working environment. In order to explore the performances which take place as attempts are made to create and indeed maintain (in some sort of way) these types of working environments, a useful starting point is Feldman's (2000) discussions of organisational routines.

Feldman (2000) undertook a longitudinal study of a housing association during which time she observed the practices involved in the provision of 'housing for approximately 10,000 single students and 4,000 members'(p. 615). In her study she looked to see what routines were in place to provide a 'living environment that helps students deal in a variety of ways with the stresses of university life' (ibid.). Focusing on the first year of a change made to the 'moving in' routine for students she highlights how

housing announced the three days of move-in to the students, and each of the residence halls handled the move in their own way. Despite various efforts to make the move go smoothly, there were invariable traffic jams and long waits as 10,000 students attempted to move in to a dozen residence halls. The result was angry parents and students and a residue of hostility that often lingered long after everyone was moved in. When the routine was changed, it was taken over by a central administrator who coordinated with the city police department to change the traffic flow so that streets in front of residence halls were all one-way and partially closed (i.e. traffic that did not need to go through these streets was diverted). Cars were allowed to pull up in front of a residence hall and were given thirty minutes to unload. Student welcoming committees with dollies helped to unload (p. 617).

Accordingly, with the introduction of the central administrator and consequent liaisons with the City Police Department the 'moving in' routine had changed and the 'invariable traffic jams and long waits' were avoided. With this in mind, Feldman (2000) highlights how an important and fundamental element of the notion of routine is that of change and the role that agency plays in this. She argues therefore that 'change occurs as a result of the participants' reflections on and reactions to various outcomes of previous iterations of the routine' (p. 611).

Returning to the empirical focus of this paper, an example of a routine operating in a health-care setting is now offered. In hospital settings within the UK, more and more patients (along with their diagnoses) are expected to follow a particular pathway; these are known as integrated care pathways (ICPs). Middleton and Roberts (2000) define these as a 'multidisciplinary outline of anticipated care, placed in an appropriate timeframe, to help a patient with a specific condition or set of symptoms move progressively through a clinical experience to positive outcomes, depending upon their initial diagnosis.' (p. 3). An ICP therefore can be seen as an effort to make routine, for patients and staff, the practices that (should/usually) surround a particular ailment or illness. Within health-care settings, however, it is important to recognise Feldman's (2000) arguments of the role that agency and change plays within organisational routines. One way to explore this is through the notion of difference as discussed by Law and Singleton (2005) where, drawing on Mol (2002), they observe that difference 'is important in health care because different healthcare practices may produce different diagnoses for individual patients. What looks like lower limb atherosclerosis in (for instance) general practice may look like something else when ankle/arm blood pres- 
sure is subsequently tested and found to be normal' (p. 341). For example, a patient may present to one health-care practice and be assigned a particular pathway (ICP) to follow but this does not necessarily mean that had they presented to a different practice site they would find themselves on the same pathway. Indeed what the following empirical discussion will demonstrate is that even in the same health-care site the differences of all involved have to be accounted for in order to explore the ongoing changes taking place as organisational routines are performed. Routines therefore should be viewed as emergent, ongoing accomplishments and as works in progress rather than finished products.

The preceding discussion has highlighted that in order to utilise the concept of routine as a way of exploring organisational change there is a need to account for agency and difference and to adopt a proximal ${ }^{1}$ and performative view. This is a view which will allow for a focus on how organisational routines are made/unmade and indeed maintained. In addition, the ongoing and emergent nature of organisational routines can be usefully explored by drawing on the notion of an obligatory point of passage (Callon, 1986: 26). To illustrate, Star and Griesemer (1989) in a study of emergent scientific work focused on the difference of all the actors involved, i.e. 'researchers from different disciplines, amateurs and professionals, humans and animals, functionaries and visionaries' (p. 387). They identified that a requirement for doing scientific work lay in the creation of common understandings within and between this diverse group which could enable these differences to be maintained. Furthermore they discuss how all the actors involved in the creation of scientific work have different ideas of what it is and what it is not. They suggest that, 'the creation of new scientific knowledge depends on communication as well as on creating new findings. But because these new objects and methods mean different things in different worlds, actors are faced with the task of reconciling these meanings if they wish to cooperate' (p. 388). In order to reconcile these different meanings, processes of standardisation/classification have to take place whereby all the actors involved come to agree that particular objects and particular methods (and indeed organisational routines) are the correct ones. In relation to this therefore, 'first, a distinction is made between inside and outside and a set of exchanges between the two is defined and regulated (which amounts to the same thing). And second, those who are outside find themselves compelled to participate in those exchanges' (Bijker and Law, 1992: 294). The inside (the standardised categories/ meanings) itself becomes the obligatory point of passage. In respect of the creation of scientific knowledge therefore agreements reached on correct objects/methods on the inside by all the actors involved are then translated to the outside.

Developing this stance further, Bowker and Star (1999) discuss how if certain categories or indeed meanings are blurred, this 'means that existing differences are covered up, merged, or removed altogether; while distinctions construct new partitions or lead to the reinforcement of existing differences. This mutual process of constructing and shaping differences through classification systems is crucial in anyone's conceptualization of reality' (p. 230). A useful way to illustrate how differences are 'covered up, merged, or removed altogether' and the role that agency and technological objects play in this can be found in Moser's (2005) utilisation of the concept 'normalisation'. ${ }^{2}$ Moser (2005) draws on the concept in her discussions of the ways in which individuals become disabled and enabled within sociomaterial practices. She highlights how disabled bodies are seen as somehow lacking the full capacities of what is perceived to be a 'normal' body and how it is this notion of 'normal' which orders and is performed in situated practice. She uses the empirical example of a disabled man named Jarle to exemplify her argument. Jarle was paralysed from the neck down and needed a ventilator to breathe. Moser relays how she had met Jarle at a seminar where he was talking about the technologies on offer to disabled people which could, potentially, enable them to live in their own homes. She describes how following the seminar he took her to see his home to demonstrate how assistive technologies enabled him to live on his own and maintain his independence. Jarle had told her that with these assistive technologies he could 'work the computer exactly the same way as "a normal" person' (p. 671). 
For Moser (2005), Jarle's story demonstrates how state ideology and policies through which notions of the 'normal' emerge actually condition the ways in which the practices of society and indeed routine lives are performed. Drawing on this example, we suggest that notions of what it is to be 'normal' can be identified as the classification system or indeed the obligatory point of passage through which we attempt to rid ourselves of our differences in order to become 'normal'. In addition, as Bowker and Star (1999) demonstrate, while classification systems serve to cover up difference, they also reinforce existing differences. Moser's (2005) adoption of the concept of 'normalisation' to explore Jarle's sociomaterial life usefully allows us to see how his differences are covered up. Paradoxically, however, this leads to the reinforcement of the notion of disability itself as being not 'normal'.

At this point, we suggest that Jarle's story and his engagement with assistive technologies demonstrates that if we are to usefully adopt a proximal view to explore the emergent, ongoing and changing nature of organisational routines, we need not only to account for the role of agency in these processes but we need also to account for the role of technological objects. As Orlikowski (2007) argues, there is often a lack of discussion of the material within organisation studies which often 'disregards or ignores the everyday materiality of organizing' (p. 1444). Drawing on this, we suggest that organisational routines are always and inevitably a result of the sociomaterial relations of which they are part. Indeed as Jarle's story highlights the work of making routine, of making normal, can be seen as a movement from one sociomaterial specificity to another that is Jarle moved from a disabled man paralysed from the neck down needing a ventilator to breathe and unable to live on his own, to a technologically enabled man who lives like a 'normal' person, what Moser and Law (1999) might call a 'good passage'. However, what is often seen as an apparently 'effortless movement from one specificity to another conceals work. It conceals pain, the effort of arraying the materials of successive specificities, of ordering them or, perhaps the shame involved in the materialities of their arrangement. So there are front stage slickness and back stage complexities, difficulties, or bad passages.' (Moser and Law, 1999: 207). This work that underpins the movement from one specificity to another plays a fundamental part in the emergence of standardising practices and organisational routines and offers a useful lens through which to think about the work taking place in the making and unmaking of organisational routines.

Bearing the preceding discussion in mind, what follows is an exploration of the sociomaterial performances taking place as attempts are made to change the organisational routine in a specific A\&E department. Focusing on a particular routine within this department known as the Manchester Triage System and the role that a set of wooden boxes play in the making of this system, we highlight some of the tensions and contradictions or 'back stage complexities' involved in these performances.

\section{Empirical discussion}

\section{The setting and change initiative}

The research setting is a busy A\&E department situated in North West England. A change of practice was introduced into the department whereby approximately 30 different GPs were brought to work individually usually in 0.5 day shifts, alongside hospital-based consultants, doctors and nurses. These GPs were employed (during their shift) by the Hospital Trust and the funding for this employment was provided from a conglomerate of which the GPs were part, alongside the Primary Care Trust (PCT). As employees of the Hospital Trust, they were bound by the same working conditions as the other practitioners, i.e. they were expected to wear 'scrubs' and follow hospital protocols, they were in effect outwardly indistinguishable from other members of the department.

The change was a radical departure from historical practice and precedent within the delivery of A\&E services in the UK. It was unusual but not unique in that it involved the co-location of different groups of medical practitioner within the same setting. This 
initiative is representative of a wider shift occurring across the UK where efforts are being made to realign the relationship between hospital-based and community-based medical services (Freeman et al., 1999; Cooke et al., 2004). This is an attempt to shift the balance of medical service provision from the hospital to the community. One of the aims of such changes is to reduce 'unnecessary' hospital admissions which come at a considerable cost to both medical services and patients (see Blunt et al., 2010, for a review of the trends of emergency admissions to hospital). Many of these initiatives see a shift in location and responsibility away from hospital-based services towards community situations and towards a greater reliance upon ever more integration of services, an integration often mediated by the development of information and communication technology (ICT) systems (see for example, Ward et al., 1996; Freeman et al., 1999; Cooke et al., 2004). However, few such initiatives have attempted a model where practitioners from the primary and secondary health providers work together within the same location and service.

\section{Research methodology}

Our access to the site was secured when we were asked to provide a qualitative evaluation of this change of practice and service delivery. This evaluation was to take place over a period of 18 months and was to be used to complement a quantitative evaluation being undertaken by the PCT. Our aim was to talk to as many of the actors involved in the initiative as possible and to use qualitative interviews (Mason, 2002) as a way of drawing out the different actors' experiences of working with different professionals (i.e. primary care working with secondary care) in different professional settings (i.e. the hospital contexts rather than their GP surgeries). We were interested in exploring how the GPs experienced working in the hospital context in terms of working alongside different professionals and with the different spatial constraints/ enablements of the A\&E department as compared with their GP surgeries. We sought to explore in an open-ended fashion 'how' and 'why' questions which had not been specified in detail prior to the interviews (Patton, 2004). We interviewed 17 of the 30 GPs involved in the initiative over the research period and approximately half of these were interviewed twice. We also interviewed on two occasions (once at the start of the initiative and the other towards the end) all of the five hospital consultants working on a permanent basis within the department. We spoke to a number of nursing staff (nine) ranging from staff nurses through to matron. In an attempt to further explore the tacit nature of routines (Cohen and Bacdayan, 1994) operating in this context we carried out a number of observations. This was to try to gain an understanding of how the department worked holistically (i.e. the urgency and flow of work processes) and to better understand how or if the participation of the GPs affected this. We observed the department mostly when the GPs were working (8:30am-6:30pm Monday to Friday), but we also carried out a number of observations outside of these hours. The purpose of this was to identify how or whether things worked differently when the GPs were not in attendance. Throughout discussions with GPs and hospital staff, and indeed watching them in our limited fashion, we were able to collect their views around the ideology surrounding the change and how things were developing in terms of their own involvement. This was an attempt to identify what continuing impact (if any) the initiative was having on those involved and their work practices and to explore whether it was seen as fulfilling its initial expectation to reduce hospital admissions via the A\&E department.

\section{A brief history}

At the start of our involvement we went to speak to the initiatives key proponent, who for the purposes of this paper, we will call John. He was one of two experienced GPs who had been working alongside hospital staff within the department for a period of approximately nine years. The two GPs, who both had an interest in emergency medicine, had been working a morning shift once a week over this period. They had 
become, over that time, an accepted and welcome part of the A\&E team-albeit only on Thursday mornings. We were told on numerous occasions throughout our interviews with various hospital staff that both GPs were more than willing to 'get their hands dirty' and deal with all types of patients that presented to the department. One might say therefore that John and his colleague 'fit' smoothly into the routine working environment of the department. John was also part of a conglomerate of local GP practices which had accumulated a sum of money that needed to be spent lest it be absorbed back into the PCT. At this time, 2010, PCTs were the overarching funding body for all health-care practices in the UK. Indeed, 'they were responsible for around 80 per cent of NHS expenditure' (Thomas and Hewitt, 2011: 1381) and managed the majority of services that people made use of.

In terms of the emergence of the initiative, John (who it will be recalled was one of its key proponents) had the positive experience of his time spent in A\&E, while within the wider context there was a huge focus on a need to change health-care provision in order to reduce costs. One way of doing this had been identified as reducing hospital admissions. In addition there was a pot of money that John and his GP colleagues had or could have access to-money which, if not used by them, would get 'lost in the system'. The idea of the initiative therefore was that this money (John had convinced his fellow GPs in the conglomerate of this, along with the PCT and the Hospital Trust) could be used to fund GPs working alongside hospital staff in this A\&E department.

\section{The vision}

The introduction of the GPs into the staff team within the A\&E department with their primary role to assist in the management of unscheduled hospital admissions required them to identify or have identified for them by triage nurses, ${ }^{3}$ patients that were felt to constitute 'complex' cases. These were cases where the patients, often elderly and presenting multiple symptoms, were sometimes admitted to hospital in order to carry out procedures to ascertain the seriousness of their condition. The idea was that the GPs could draw on their professional judgement, experience and knowledge of the patient and services available within the wider community in an attempt to prevent unnecessary admissions. This judgement, it was argued by the proponents of the change, could be better made by the GPs rather than hospital-based doctors due to a wider knowledge of local services and their daily engagement with such patients in their surgeries. The GPs were also considered to hold a different model of risk when presented with such multiplicity of symptoms and were seen as being less inclined to admit such patients into hospital. As one GP responded when asked for his interpretation of the change initiative,

The theory is that there aren't the hospital beds available to support the population and that some of the admissions to those hospital beds might have been prevented by using clinicians who are perhaps used to dealing with cases in the community and who have contact with different support mechanisms in the community.

For example, many elderly patients presenting with shortness of breath (according to the data generated from our discussions with GPs) were unlikely to require hospital admission but could be dealt with in the community. For the hospital consultants and doctors however the risk associated with shortness of breath in an elderly patient was often seen as too high to allow for discharge. In many instances the patient would be admitted into hospital for further observations - this we were told was particularly the case when junior hospital doctors were involved. Often the patient would be discharged the following day or relatively quickly. In some other cases, however, records show that elderly patients, particularly those who lived alone, became longer term patients.

\section{The everyday organisational routine}

Within this particular A\&E department, there operated a system of classification which served to routinise the ongoing work of the department. This system, known as the 
Manchester Triage System (MTS), is commonly used by A\&E staff across Europe and Australasia. It is a system the outcome of which is the determination of a patient's urgency treatment level. To illustrate, Roukema et al. (2006) discuss how, 'the MTS provides clarity about maximum allowed waiting time for the different levels of urgency: "emergent" (red) needs instantaneous evaluation, "very urgent" (orange) needs evaluation within $10 \mathrm{~min}$, "urgent" (yellow) within $60 \mathrm{~min}$, "standard" (green) within $120 \mathrm{~min}$ and "non-urgent" (blue) can wait for up to $240 \mathrm{~min}^{\prime}$ (p. 906). The system has been operating within this A\&E department for many years and is outwardly represented by a set of wooden boxes (see Figure 1 below). The system acted as a guide for all actors involved in these particular working practices and served to actively reconcile different meanings and working methods. These standardised categories and meanings provided an obligatory point of passage (Callon, 1986) through which all involved (i.e. consultants, GPs, nurses, patients, paper triage cards and so on) had to pass.

What routinely happens within the A\&E department is people present to reception (unless arriving by ambulance), details are taken, entered on the computer system and patients are sent through to a waiting room. They are then called into the triage room to be seen by the triage nurse. The triage nurse assesses the type and level of urgency of treatment for that particular patient, fills out a triage card and places it in the relevant triage box. The next available hospital consultant/doctor then goes to the triage boxes, takes out the triage card (determined by urgency and relevant treatment time) and attends to that patient. Acute emergencies, usually ambulance cases are taken straight through to resuscitation and take priority over all other cases.

With the introduction of the GPs into the A\&E department, the triage boxes became a site of some contestation and ambiguity. Indeed, one might think of this technological object as being, prior to the introduction of the GPs, something of an immutable mobile (Latour, 1987: 227) whereby 'it holds shape in two importantly different ways. On the one hand, it does so in physical or geographical space. On the other, it holds shape in some relational and possibly functional manner where it may, to say it quickly, be imagined as a more or less stable network of associations' (Law and Singleton, 2005: 335). ${ }^{4}$ Prior to the change initiative, the triage boxes were encountered by the hospital staff in much the same way. Hospital consultants/doctors would take (determined by time and urgency) the first card in the relevant box and treat that patient accordingly. However, the GPs were asked to use the system differently and to sift through the triage boxes and 'cherry pick' the 'complex cases' in an effort to reduce admissions. Drawing on Moser and Law (1999), we suggest that prior to the introduction of the GPs,

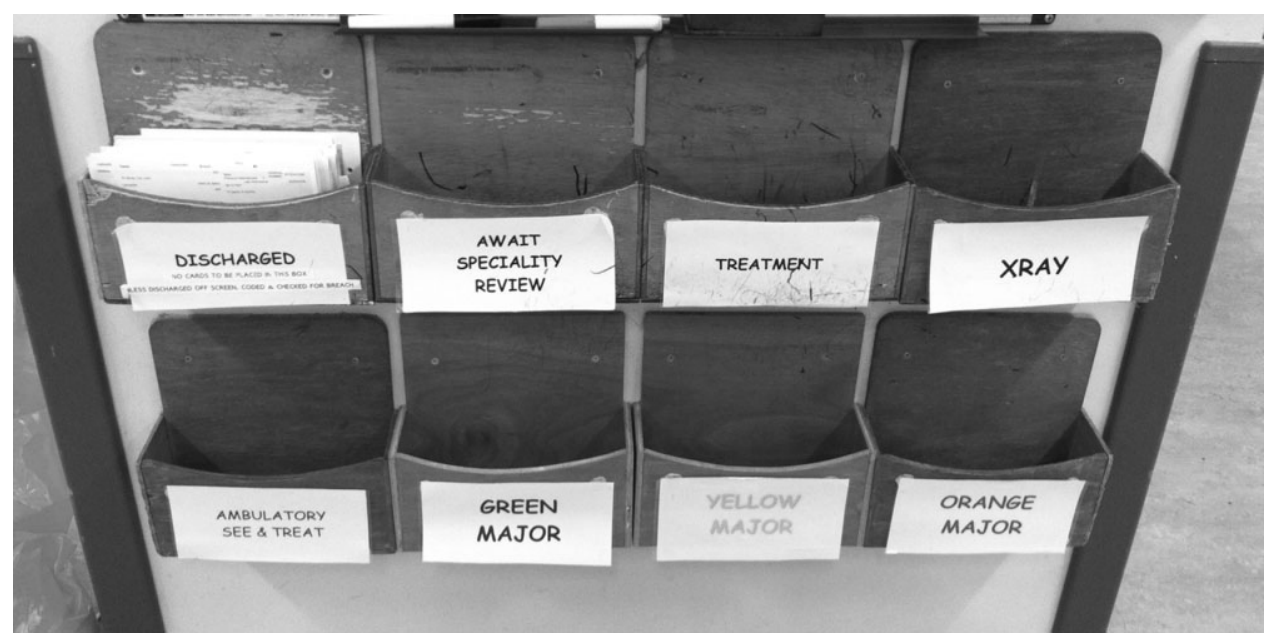

Figure 1: The triage boxes-an obligatory point of passage within this setting 
the movement of patients and their needs (as inscribed on paper cards) from one specificity that is (from the triage nurse) to another (the relevant triage box) and to another (the hospital doctor) could be seen as relatively effortless and smooth, a 'good passage'. However, the attempt at change (i.e. the introduction of the GPs) problematised this smoothness and began to uncover and indeed create some of the tensions and contradictions/'back stage complexities', inevitably encountered as attempts were made to reorganise these routine work practices.

To illustrate, as the change was being implemented and we were talking to some of the actors involved in the department, we began to get a sense of frustration from both the hospital staff and the majority of the GPs. When speaking to the hospital consultants $^{5}$ there was a sense of cynicism in relation to the idea that the GPs would reduce admissions. This was evident when these consultants were asked about the ability of GPs to reduce admissions. It was made clear to us that they did not see how a GP dealing with a particular patient would necessarily lead to them being more able to save an admission than a consultant/hospital doctor. One of the consultants asked the question 'who's to say their treatment of a patient would be any different than mine?'. In fact the lead consultant who had initially promoted the initiative (but was to leave some 12 months into it) also raised this as an issue. For him, however, the more patients that presented to $A \& E$ the more viable and stable his department would remain. We were informed by him that one way in which the department's use value was assessed/ accounted for related to patient numbers using the department, whether admitted or not. In other words, the busier the department, the more likely it was to be kept open.

In terms of the 15 GPs we spoke to over the research period, a number of issues were raised in terms of their own frustrations. For example, some did not want to be there, some did not like 'cherry picking' patients and some were anxious about dealing with the types of patients that may present at the hospital (e.g. those presenting with medical emergencies which might be better dealt with by emergency hospital doctors/ consultants). Most indicated that they were concerned with not knowing where things were (e.g. stethoscopes and other objects) and as a result of the busy and frantic nature of the department ${ }^{6}$ they did not like to ask so would just try to muddle through.

When talking to the nurses, it became apparent that many of them did not really know why the GPs were there and saw them as another hospital doctor and, as a result, expected them to work in much the same way. One of the GPs informed us that he felt 'most of the nurses didn't know what we're here for'.

Confusion was evident therefore as to why the GPs were there and what their role entailed, but all of those involved had to work there, and the work that had to be carried out had to be done so calmly and efficiently. The organisational routine therefore had to be maintained, however, as a result of the introduction of the GPs this began to destabilise. What follows are some empirical examples of the role that the triage boxes played in the destabilising and subsequent re-stabilising (which is not to suggest that this re-stabilisation would remain fixed) of the A\&E department as this change was implemented. In addition the following examples demonstrate how these boxes often become a site of contestation and conflict-a site where some of the 'back stage complexities' involved in ongoing and emergent routine making and unmaking can be explored. As Moser and Law (1999) highlight, when dealing with specificities and the movement between different specificities (i.e. the movement of the patient from reception, to the triage nurse, to the triage card, to the triage box, to the relevant doctor/GP, and so on) we need to remind ourselves that specificities 'are specific because they come in the form of networks of heterogeneous materials' (p. 201)-they are both social and material.

During our discussions with the GPs, we asked them questions relating to the 'sorting out' of patients, the role of the triage boxes in these 'sorting out' processes and the impact this was having on their working practices within the department. One GP indicated that,

If there is a road traffic accident or somebody has fallen over and has broken their leg that is not something that I've got any experience with, so I try and choose those cases where I've got the experiences and the skills to use them most appropriately. 
This GP seemed to be fairly relaxed and confident about his role and the use of the triage boxes. He seemed comfortable with going to the boxes to select cases which he saw as appropriate for him to treat in terms of utilising his own particular skill set. We might say therefore that he saw himself as being there in a specialist GP role (the ideal of the initiative) rather than as an 'extra pair of hands' (many of the hospital staff we spoke to perceived the GP role to be just that).

We were told by another GP that,

I select my own patients to a point but when there is nothing particular for me to do I will just take the next card that's in the box, just to get the people through. I think there's a lot of wariness from one or two consultants in the department so I think it's important to be seen to be doing donkey work as well.

Again this GP seemed fairly relaxed and confident in respect of what he was there to do. However, he was keen to be seen to be doing the everyday 'donkey work' so as to keep the consultants happy and to keep himself busy (he indicated he enjoyed the variety of work and some of the pressure that came with it).

Another GP said,

I try to go through the boxes to see what might be a suitable thing to deal with. The danger is that you find yourself a bit out of your depth or trying to deal with things you're not absolutely sure about. I think that's the difficulty of it because you can't really get to the cases where you can make a difference when having to deal with some of the cases where you can't.

This GP was finding himself, at times, a little out of his depth and arguably dealing with cases that did not fit the ideal of the initiative (i.e. complex cases within his particular comfort zone that might be best dealt with out in the community). This GP tended to take the first card in the relevant triage box or the cases that were given to him by nursing staff rather than 'cherry pick' cases. He was very nervous during the interview and actually stopped five minutes into it. He asked one of the authors during the interview to ring him during his GP practice hours when he would be able to talk more freely. He said, 'the consultants will come down on me like a ton of bricks if they see me talking to you'.

Some six months after the implementation of the initiative, the lead consultant was re-interviewed and asked how his staff found working with the GPs. He said, 'There have been issues when it's busy and there are individuals [GPs] not wanting to see anyone out of their comfort zone'.

So arguably not working out of their comfort zone was frowned upon by hospital staff and yet the ideal of the initiative was to keep GPs within their comfort zone in order that they utilise their specialised skills in a different environment.

Approximately 12 months into the initiative, it was becoming apparent during our discussions with all the actors involved and our observations that things were beginning to settle down. A minority of the GPs still seemed comfortable with 'cherry picking' and would not get involved in anything else. For the majority, however, although they would occasionally select appropriate/complex cases or indeed the nursing staff (now familiar with the GP role) would select cases for them, in many instances they began to act like the hospital staff and would engage with the triage system as the hospital staff did. Accordingly, they would not necessarily pick out the patients that they felt they might have a chance to send home but would take the first triage card in the relevant box and do their best to deal with that case. There may be a number of reasons for this which could be related to them enjoying working within emergency medicine and/or becoming more comfortable and familiar with the department. Maybe the hospital staff were becoming more familiar and accepting of the GP role and taking this into account when performing their own routine. Whatever the case may be, the relations and the negotiations taking place of which the triage system was a part were both changing that is some 'cherry picking' was becoming acceptable, and staying the same, that is if the department was quiet or there were no specific GP cases, the majority of GPs were operating like hospital doctors. 


\section{Discussion}

Many complex and ambiguous issues arise within the department as different people encounter these triage boxes (this obligatory point of passage). As a result, this set of boxes, which arguably plays a key role in the routinisation of the department, comes under some pressure. In addition, the GPs (the majority of them) who were asked to use these triage boxes differently also come under pressure and the role that they are being asked to occupy begins to break down that is ' $i t^{\prime}$ 's important to be seen to be doing the donkey work as well'. For the minority however, the GP role as defined by the initiative, that is to use specialist skills to reduce hospital admissions by 'cherry picking' patients, was and remained throughout their performances well-defined, a good fit. As indicated, the GPs that did adopt the role as defined by the initiative were limited, and the majority we spoke to were finding it difficult to avoid 'doing the donkey work as well'. The role of the newly introduced GPs asks them to work across the organising principles embedded within the triage boxes, to use their professional experience and expertise to isolate and 'cherry pick' the 'complex cases' where they perceive there to be a danger of 'unnecessary' admission to hospital and to stop it. These triage boxes work as part of a network of sociomaterial relations and play a key role in stabilising/making routine these relations. However, when new actors 'cut' into the network the routine begins, potentially, to destabilise. In addition when a stabilised network is 'cut' into by these new actors/GPs, the defined GP role for the majority of the GPs we spoke to begins to destabilise.

In terms of the roles of the majority of the GPs, one might say that the GP identity within this setting is about negotiation, change and compromise. For example, many of the GPs could be said to be moving from the GP role defined by the initiative to the role of GP/hospital doctor and no doubt at times back again. Indeed, as Dugdale (1999) suggests, this movement can be seen as, 'a continued oscillation between singularity and multiplicity rather than a movement from oscillation to a resting place' (p. 125).

Negotiation, change and compromise can also be identified when moving from and within one sociomaterial specificity to another in some cases through 'good passages' and in others through 'bad passages' (Moser and Law, 1999). Initially therefore the GPs that would 'cherry pick' or who did find the defined role a good fit could be said to have a 'good passage' from one specificity to another, but the GPs that felt they should do the 'donkey work' a 'bad passage'- 'the danger is you find yourself a little bit out of your depth'. However, the notion of 'good and bad passages', although useful for this particular analysis, do not take us far enough as these can also be said to oscillate or more aptly undergo ongoing reconfigurations. For example, the GPs initially who 'cherry picked' patients and would not treat anyone else had tended to either leave or start to work in some instances (i.e. when there is nothing else to do) like the hospital doctors. The nurses also, over time, had come to learn what the GPs could offer the department and began to select 'appropriate' GP patients and pass the relevant cards to them and so on and so forth. The GPs who arguably could be said to have initially had a 'good passage' (in the sense that they stuck to the defined role-for whatever reasons) either left or began to work differently. The GPs that did the 'donkey work' from the start who, we suggest, could be said initially to have had a 'bad passage' tended to stay, and the 'bad passage' for them could be said to have become 'good'-many of those GPs that did stay told us that over time they had begun to really enjoy their time in the $A \& E$ department and felt that they now fit into something of a dual role that is that of GP/hospital doctor. It seemed that as time had passed (18 months), most of the people involved in the A\&E department had come to see the value of the GPs and vice versa. What was happening towards the end of our involvement was the remaining GPs were routinely selecting, and indeed being given by the triage nurses, triage cards for those patients that might be better treated outside in the community. However, if times were busy or these types of patient had not presented, then the GPs (or most that were left) would do the 'donkey work' quite willingly and happily. Accordingly, we see not only an ongoing oscillation between singularity and multiplicity (i.e. the GP role to the role of GP/hospital doctor and back again) but also, over time, an ongoing reconfiguration 
of 'good passages' and 'bad passages' (i.e. doing the 'donkey work' was initially seen as 'bad' but over time became 'good', a way of fitting into the dual role of emergency GP/hospital doctor).

This was further illustrated on a visit to the department (some 18 months after the first) where one of the hospital consultants who had been extremely cynical at the start of the initiative told us that having GPs in the department had been of immense value and the effect was twofold. For as this consultant (newly promoted to clinical lead of the department) told us, 'they have an effect because it's an extra pair of hands. However it is also effective because of the experience they have' thus indicating the GPs were now complementary to them. Drawing on Star and Griesemer (1989), one might suggest that what is happening here is that new actors and new methods need to be reconciled. This in turn means that processes of standardisation/classification have to take place. Although the obligatory point of passage remains the same (i.e. everything passes through the triage boxes), what passes through does so slightly differently, albeit these differences over time have been covered up and are now seen as the routine way of working or indeed, a 'good passage'. In terms of what he calls the 'problem GPs' (i.e. the ones that would 'cherry pick' patients and do nothing else) he tells us that the 'lazy ones' tend to belong to one and the same practice. He indicated that these 'lazy' GPs did not want to be there and only came because of the extra money on offer to them. He said that the initiative itself had changed over time and that 'the lazy ones [practices] have filtered themselves out'. In terms of the differences that could not be covered up or refused to be covered up (i.e. the GPs that would not do the 'donkey work' and left) one might say that these led to the reinforcement of existing differences (Bowker and Star, 1999) often associated (by the hospital staff in this instance) with the laziness of GPs. From the perspective of the consultant, the department was left with (or nearly as there was still one 'lazy' practice that needed to be filtered out) a group of GPs which he eventually came to see as playing a fundamental role in maintaining the newly established/changed organisational routine of his department.

\section{Conclusions}

In this paper we have adopted a multilevel sociomaterial exploration of a planned change initiative introduced within an A\&E department in North West England. We wish to highlight four aspects of this exploration as being particularly relevant to the present discussion. First, in order to understand organisational change within this setting, there is a requirement to focus on the processes by which organisational routines emerge and the role of the obligatory point of passage (a set of wooden boxes), which has highlighted the roles of agency, difference and standardisation/categorisation practices in the making and unmaking of routines. Second, the longitudinal nature of the study and the complementary adoption of the proximal view has allowed for a focus on the 'continuous and unfinished' (Cooper and Law, 1995) which has served to uncover the continued oscillation from singularity to multiplicity (i.e. from the GP role to the GP/hospital doctor role and back again) that takes place within these processes. Third, by focusing on change and paying attention to the movement from singularity to multiplicity, further movement has been highlighted within and between sociomaterial specificities - as exemplified by the notion of 'good passages' and 'bad passages' (Moser and Law, 1999). Finally, it has been demonstrated how these 'good passages' and 'bad passages' are not fixed in time but are undergoing constant reconfiguration.

By drawing on literature from the fields of Organisation Studies and STS, the paper offers a fresh academic gaze on change from both within and outside the academic study of technology, work and employment. Accordingly, and in keeping with STS traditions of close attention to the richness of the empirical, the approach used does not offer answers, directions or solutions to problems of organisational change or its management. It does, however, offer 'in conformity with the methodological commitment to follow the actors no matter how they act' a mapping of the way in which actors 'define and distribute roles, and mobilize and invent others to play these roles. Such roles may be social, political, technical or bureaucratic in character; the objects that are 
mobilized to fill them are also heterogeneous and may take the form of people, organizations, machines or scientific findings' (Law and Callon, 1988 p. 285).

To conclude, this has been a story about analysing change in a method which values multiplicity which attempts to operate at different levels within a particular setting and seeks to include the role played by technological objects. What then has been demonstrated is that change can be viewed as an ongoing and recursive sociomaterial relationship or, as Bloomfield and Vurdubakis (1994) might argue, as 'different moments in the unfolding biography of the artefact' (p. 134) and the social relations of which it is part.

\section{Acknowledgements}

We would like to thank the three anonymous reviewers and the editors of this special issue whose comments and suggestions have helped us to further develop and refine the argument presented here. Thanks also to the various individuals who gave freely of their time as part of the fieldwork discussed in this paper.

\section{Notes}

1. Cooper and Law (1995) discuss how, 'Distal thinking privileges results and outcomes, the "finished" things or objects of thought and action. It privileges the ready-made. So the distal is what is preconceived, what appears already constituted or known, what is simplified, distilled; it's a bit like fast food-packaged for convenience and ease of consumption. Proximal thinking deals in the continuous and "unfinished; it's what is forever approached but never attained, what is always approximated but never fully realized. The proximal is always partial and precarious, forever fated to repeat itself in an effort to reach (but never attain) completion.' (p. 239)

2. For Foucault (1977), 'The judges of normality are present everywhere. We are in a society of the teacher-judge, the doctor-judge, the social-worker-judge. It is on them that the universal reign of the normative is based; and each individual, wherever he [sic] may find himself, subjects to it his body, his gestures, his behaviour, his aptitudes, his achievements.' (p. 304)

3. Triage nurses were there to assess/diagnose what treatment patients might need prior to being seen by more qualified medical staff.

4. We know this as a result of our discussions with staff who worked in the A\&E department prior to the implementation of the initiative.

5. Apart from the lead consultant who had been the one who had played a role in the implementation of the initiative and accepted that it was a positive thing for his department and was happy for GPs to work alongside his staff.

6. The department we were told was always understaffed in relation to the amount of patients presenting at the department for a variety of reasons. We were also told and observed that spatially it was too small i.e. there were not enough beds/treatment rooms for the volume of patients.

\section{References}

Bijker, W.E. and J. Law (eds) (1992), Shaping Technology/Building Society: Studies in Sociotechnical Change (Cambridge, MA: MIT Press).

Bloomfield, B.P. and T. Vurdubakis (1994), 'Re-Presenting Technology: IT Consultancy Reports as Textual Reality Constructions', Sociology 28, 2, 455-477.

Blunt, I., M. Bardsley and J. Dixon (2010), Trends in Emergency Admissions 2004-2009, Nuffield Trust Report. http://www.nuffieldtrust.org.uk/sites/files/nuffield/Trends_in_emergency_ admissions_REPORT.pdf (accessed 1 December 2011).

Bowker, G.C. and S.L. Star (1999), Sorting Things Out: Classification and Its Consequences (Cambridge, MA: MIT Press).

Callon, M. (1986), 'The Sociology of and Actor-Network: The Case of the Electric Vehicle', in M. Callon, J. Law and A. Rip (eds), Mapping The Dynamics of Science and Technology (London: Macmillan), pp. 9-34.

Cohen, M.D. and P. Bacdayan (1994), 'Organizational Routines Are Stored as Procedural Memory: Evidence from a Laboratory Study', Organizational Science 5, 4, 554-568. 
Cooke, M., J. Fisher, J. Dale, E. McLeod, A. Szczepura, P. Walley and S. Wilson (2004), Reducing Attendances and Waits in Emergency Departments: A Systematic Review of Present Innovations, [Report-University of Warwick]. http://www.sdo.nihr.ac.uk/files/project/29-final-report. pdf (accessed 7 January 2011).

Cooper, R. and J. Law (1995), 'Distal and Proximal Vision of Organization', in S. Bacarach, P. Gagliardi and B. Mundell (eds), Studies of Organizations in the European Tradition (Greenwich: Jai Press), pp. 237-274.

Dugdale, A. (1999), 'Materiality: Juggling Sameness and Difference', in J. Law and J. Hassard (eds), Actor Network Theory and After (Boston, MA: Blackwell Publishers), pp. 113-135.

Feldman, M.S. (2000), 'Organizational Routines As a Source of Continuous Change', Organization Science 11, 6, 611-629.

Foucault, M. (1977), Discipline and Punish (London: Penguin).

Freeman, G.K., R.P. Meakin, R.A. Lawrenson, G.M. Leydon and G. Craig (1999), ‘Primary Care Units in A\&E Departments in North Thames in the 1990s: Initial Experience and Future Implications', British Journal of General Practitioners 49, 439, 107-110.

Latour, B. (1987), Science in Action: How to Follow Scientists and Engineers through Society (Cambridge, MA: Harvard University Press).

Law, J. and M. Callon (1988), 'Engineering and Sociology in a Military Aircraft Project: A Network Analysis of Technological Change', Social Problems 35, 3, 284-297.

Law, J. and V. Singleton (2005), 'Object Lessons', Organization 12, 3, 331-355.

Mason, J. (2002), Qualitative Researching, 2nd edn (London: Sage).

Middleton, S. and A. Roberts (2000), Integrated Care Pathways (Oxford: Butterworth Heinemann).

Mol, A. (2002), The Body Multiple: Ontology in Medical Practice (London: Duke University Press).

Moser, I. (2005), 'On Becoming Disabled and Articulating Alternatives: The Multiple Modes of Ordering Disability and Their Inferences', Cultural Studies 19, 6, 667-700.

Moser, I. and J. Law (1999), 'Good Passages, Bad Passages', in J. Law and J. Hassard (eds), Actor Network Theory and After (Boston, MA: Blackwell Publishers), pp. 196-219.

Orlikowski, W.J. (2007), 'Sociomaterial Practices: Exploring Technology at Work', Organization Studies 28, 9, 1435-1448.

Patton, M.Q. (2004), Qualitative Research and Evaluation Methods, 4th edn (London: Sage).

Roukema, J., E.W. Steyerberg, A. van Meurs, M. Ruige, J. van der Lei and H.A. Moll (2006), 'Validity of the Manchester Triage System in Paediatric Emergency Care', Journal of Emergency Medicine 23, 12, 906-910.

Star, S.L. and J.R. Griesemer (1989), 'Institutional Ecology, "Translations” and Boundary Objects', Social Studies of Science 19, 3, 387-420.

Thomas, P. and J. Hewitt (2011), 'Managerial Organization and Professional Autonomy: A Discourse-Based Conceptualization', Organization Studies 32, 10, 1373-1393.

Ward, P., J. Huddy, S. Hargreaves, R. Touquet, J. Hurley and J. Fothergill (1996), 'Primary Care in London: An Evaluation of General Practitioners Working in an Inner City Accident and Emergency Department', Journal of Accident and Emergency Medicine 13, 1, 11-15. 